\title{
Justiça restaurativa no Brasil \\ Possibilidades a partir da experiência belga
}

\author{
Restorative justice in Brazil \\ Possibilities from the Belgian experience
}

Daniel Achutti*

\begin{abstract}
Resumo: $O$ artigo apresenta o sistema de justiça restaurativa adotado pela legislação belga, e demonstra as formas pelas quais os mecanismos restaurativos interagem com o sistema de justiça criminal. Descreve as dificuldades iniciais enfrentadas, nos primeiros anos da década de 1990, durante as primeiras experiências com mediação de conflitos na Bélgica, bem como a forma como foram superadas. Ao final, a partir de uma perspectiva crítica, projeta possibilidades para a adoção da justiça restaurativa no Brasil.
\end{abstract}

Palavras-chave: Justiça restaurativa. Justiça criminal. Bélgica, Brasil.

Abstract: The paper presents the restorative justice system adopted by the Belgian law, and demonstrates the ways in which restorative mechanisms interact with the criminal justice system. Describes the initial difficulties faced in the early 1990s, during the first experiences with conflicts mediation in Belgium, as well as how they were overcome. At the end, from a critical perspective, designs possibilities for the adoption of restorative justice in Brazil.

Keywords: Restorative justice. Criminal justice. Belgium. Brazil.

Pouco se conhece, no Brasil, sobre o mecanismo de administração de conflitos criminais denominado justiça restaurativa. Raros são os trabalhos a respeito, e a quantidade de pessoas que efetivamente compreende tal sistema é baixa, embora em número crescente. Parte de seus críticos (majoritariamente juristas), apesar de desconhecer as particularidades do sistema restaurativo, costuma referir que se trata de um "modelo utópico" ou que "somente seria

* Doutor em Ciências Criminais pela Pontifícia Universidade Católica do Rio Grande do Sul (Pucrs), advogado, pesquisador e professor de Direito Penal e Processual Penal no Centro Universitário La Salle, em Canoas, RS, Brasil. <dachutti@terra.com.br>.

\begin{tabular}{|l|l|l|l|l|l|}
\hline Civitas & Porto Alegre & v. 13 & n. 1 & p. 154-181 & jan.-abr. 2013 \\
\hline
\end{tabular}


aceitável para lidar com crimes mais leves", ou ainda se utiliza de qualquer outra referência igualmente infundada.

No entanto, apesar destas constatações, o presente trabalho não servirá para uma exposição teórica detalhada sobre os principais aspectos e características do referido mecanismo, ${ }^{1}$ mas antes para a apresentação de um modelo concreto de utilização de práticas restaurativas e as suas intersecções com o sistema de justiça criminal. Ou seja, pretende-se demonstrar que, para além de uma mera "possibilidade utópica", este modelo de administração de conflitos já é realidade em alguns locais.

Evidentemente, questões teóricas centrais - como conceitos-chave e noções gerais - serão também apontados, ainda que de forma sucinta. $\mathrm{O}$ foco, todavia, será a exposição do modelo belga de justiça restaurativa, conhecido internacionalmente por seus mais de vinte anos de experiências e pelo criterioso e constante acompanhamento realizado por pesquisadores, atores jurídicos e voluntários sobre o seu funcionamento.

Apesar de não ser possível fazer um estudo comparativo entre os sistemas de justiça brasileiro e belga, em razão das diversas e consideráveis diferenças que separam os dois países - e, particularmente, pela inexistência de um sistema restaurativo institucionalizado no Brasil - a experiência com a justiça restaurativa na Bélgica² chama a atenção por diversos fatores, que se não servem como parâmetro comparativo direto, servem perfeitamente como um modelo ilustrativo de um caso bem sucedido.

Por tal motivo, inicialmente será realizada uma breve exposição conceitual sobre a justiça restaurativa e, a seguir, será exposto o modelo belga. A preocupação teórica que conduz o presente trabalho diz respeito à verificação da possibilidade de redução do uso do sistema penal por meio da aplicação de mecanismos restaurativos. Ao final, levando em consideração as particularidades brasileiras, serão considerados possíveis entraves para a adoção deste sistema no país.

1 Para uma compreensão ampla e detalhada da Justiça Restaurativa, sugere-se a leitura das seguintes obras: Sica (2007) e Pallamolla (2009).

2 A Bélgica é um estado federal, dividido em três regiões: a região de Flandres, ao norte, onde se fala flamengo (comunidade flamenca); a Valônia, ao sul, onde se fala francês (comunidade francesa); e Bruxelas, capital bilíngue, onde o francês e o holandês são línguas oficiais. Ao leste existe ainda uma pequena comunidade germanófona, com cerca de 70.000 habitantes. Sede de diversas organizações internacionais, como a União Europeia e a Otan, o sistema político do país é o da monarquia constitucional. Além do parlamento federal, cada região tem o seu próprio parlamento, assim como as três diferentes comunidades, o que faz com que o seu sistema de organização política seja consideravelmente complexo. Cada parlamento (sete, no total) possui atribuições e competências diferentes, de forma que cada comunidade e região seja administrada conforme as suas peculiaridades. Fonte: sítio eletrônico oficial da União Europeia <http://www.europa.eu>. Acesso em: 28 fev. 2012. 


\section{Justiça restaurativa: breves apontamentos}

Em grande medida, os primeiros trabalhos sobre justiça restaurativa refletiram uma insatisfação crescente com o sistema de justiça criminal tradicional - apresentado desde um panorama sombrio e ineficaz que, desse modo, justificaria a adoção de um novo modelo (Morris, 2002; Hoyle, 2010; Van Ness e Strong, 2010).

Conforme Braithwaite (2002, p. 8-10), o interesse pela justiça restaurativa no ocidente ressurgiu a partir de um programa de reconciliação entre vítima e ofensor na cidade de Kitchener, Ontario, no Canadá, no ano de 1974. Tratavase de programas comunitários que buscavam mediar conflitos entre vítimas e ofensores após a aplicação da decisão judicial.

Ainda conforme o autor (Braithwaite, 2002, p. 8-10), nos anos 1980, os trabalhos de Howard Zehr (1985, 1995), Mark Umbreit (1985, 1994), Kay Pranis (1996), Daniel Van Ness (1986), Tony Marshall (1985) e Martin Wright (1982), somados aos esforços dos juízes neozelandeses Mick Brown e Fred McElrea e à polícia australiana, a justiça restaurativa se tornou um importante movimento social em favor da reforma da justiça criminal na década seguinte, quando Lode Walgrave, Alisson Morris, Gabrielle Maxwell, Kathleen Daly, Heather Strang e Lawrence Sherman iniciaram suas pesquisas a partir de uma perspectiva crítica e, ao mesmo tempo, construtiva. ${ }^{3}$

Pelas palavras de Gerry Johnstone e Daniel Van Ness (2007, p. 5), a justiça restaurativa é "um movimento social global que apresenta enorme diversidade. $\mathrm{O}$ seu objetivo maior é transformar a maneira como as sociedades contemporâneas percebem e respondem ao crime e a outras formas de comportamentos problemáticos".

Referem os autores, entretanto, que não é possível estabelecer um consenso acerca da sua definição, bem como da verdadeira natureza do que o movimento da justiça restaurativa procura:

[...] alguns consideram a justiça restaurativa como uma nova técnica social ou programa que pode ser usado no interior dos nossos sistemas de justiça criminal. Outros procuram, em última análise, abolir grande parte do edifício de punição do estado e substituí-lo por respostas baseadas na comunidade que ensinam, curam, reparam e restauram vítimas, autores de crimes e suas comunidades. Outros, ainda, aplicam a visão de cura e restauração a todos os tipos de conflitos e danos. $\mathrm{Na}$ verdade, o objetivo final e foco principal, eles sugerem, deveria ser a mudança da maneira como vemos a nós mesmos e nos relacionamos com os outros na vida cotidiana (Johnstone; Van Ness, 2007, p. 5).

\footnotetext{
3 Conferir também em Strang (2002, p. 46-49).
} 
Em ressonância com os autores, Raffaella Pallamolla (2009, p. 53) refere que, além da problemática da definição da natureza da justiça restaurativa, as dificuldades

[...] também atingem os objetivos deste modelo, direcionados à conciliação e reconciliação entre as partes, à resolução do conflito, à reconstrução dos laços rompidos pelo delito, à prevenção da reincidência e à responsabilização, dentre outros, sem que estes objetivos, necessariamente, sejam alcançados ou buscados simultaneamente em um único procedimento restaurativo.

Conforme Van Ness e Strong (2010, p. 23), não há um órgão encarregado de determinar o que é e o que não é justiça restaurativa: este campo se desenvolveu aos poucos, ao longo de determinado período temporal e em diferentes locais ao redor do mundo. O que é considerado restaurativo hoje se desenvolveu de forma independente do pensamento e da teoria restaurativa, e veio a influenciar e ser influenciado pelas tentativas de conceituações dos teóricos da área. Referem ainda os autores (Van Ness; Strong, 2010, p. 93) que "inovações oriundas do exterior da justiça restaurativa, tais como [os mecanismos de] assistência à vítima, policiamento comunitário, e cortes de resolução de problemas, aparentam refletir elementos do pensamento restaurativo".

Dessa forma, ainda não é possível estabelecer uma definição amplamente aceita sobre o que é a justiça restaurativa (Pallamolla, 2009). Para Strang (2002, p. 46), apesar da ampla diversidade dos programas de justiça restaurativa, essencial a todos eles é o princípio da direta participação de vítimas e ofensores, o que Carolyn Hoyle (2010, p. 2) considera como a

[...] inclusiva e colaborativa natureza do foco na resolução dos problemas da justiça restaurativa, e para uma intervenção ser considerada como restaurativa, as partes devem se juntar para dialogar como fazem na conferência restaurativa e na mediação direta.

Desde a percepção do crime como um dano causado a uma pessoa, e não como uma violação à lei (Zehr, 2008, p. 174), Shapland et al. (2006, p. 507) estão de acordo com Strang (2002) e Hoyle (2010), ao mencionar que o aspecto fundamental da justiça restaurativa é o fato de as partes considerarem e decidirem, elas mesmas, o que deve acontecer em relação às consequências 
do delito. ${ }^{4}$ Conforme Alisson Morris (2002, p. 599), "vítimas, ofensores e 'comunidades de cuidado' se juntam e, com a ajuda de um facilitador, buscam resolver como lidar com a ofensa, com as suas consequências e as suas implicações para o futuro".

Vincenzo Ruggiero (2011, p. 101), por sua vez, sugere que a justiça restaurativa é "um processo que traz os atores e a comunidade afetada por uma situação problemática de volta à condição na qual o problema surgiu", e refere que este modelo de justiça funciona a partir do envolvimento direto das partes, de modo que estas serão as responsáveis por encontrar uma solução para o caso.

Tal característica vai ao encontro, igualmente, do elemento republicano que Braithwaite (2002) procura atribuir ao procedimento restaurativo, uma vez que prevê a participação ativa (e não passiva) das pessoas diretamente afetadas pelo evento danoso. Para Leonardo Sica (2007, p. 10), "mais amplamente, qualquer ação que objetive fazer justiça por meio da reparação do dano causado pelo crime pode ser considerada como 'prática restaurativa'".

Segundo Howard Zehr (2008, p. 192),

[...] o primeiro passo na justiça restaurativa é atender às necessidades imediatas, especialmente as da vítima. Depois disso a justiça restaurativa deveria buscar identificar necessidades e obrigações mais amplas. Para tanto o processo deverá, na medida do possível, colocar o poder e a responsabilidade nas mãos dos diretamente envolvidos: a vítima e o ofensor.

Embora a reconhecida dificuldade de definição da justiça restaurativa, há um relativo consenso desde o conceito de Tony Marshall (Braithwaite, 2002, p. 11; Strang, 2002, p. 44; Pallamolla, 2009, p. 54; Hoyle, 2010, p. 1; Walgrave, 2008, p. 18; Shapland et al., 2006, p. 506; Ruggiero, 2011, p. 101; etc.), que a define da seguinte maneira: "justiça restaurativa é um processo pelo qual as partes envolvidas em uma específica ofensa resolvem, coletivamente, como lidar com as consequências da ofensa e as suas implicações para o futuro" (Marshall, 1996, p. 37).

Apesar da ampla referência à conceituação acima, ela não está isenta de críticas, e vale apontar, a esse respeito, as considerações de Braithwaite

4 Para Alisson Morris (2002, p. 598), “a justiça restaurativa devolve as decisões sobre a melhor maneira de lidar com a ofensa aos mais afetados - vítimas, ofensores e suas 'comunidades de cuidado' - e dá prioridade aos seus interesses. Assim, o estado não possui mais o monopólio sobre a tomada de decisão; os produtores das decisões são as próprias partes". 
(2002, p. 11) e Walgrave (2008, p. 18-19): o primeiro ressalta que a definição de Marshall não menciona quem ou o quê deve ser restaurado, e tampouco define os valores centrais da justiça restaurativa, enquanto o segundo salienta que a definição não estabelece se o resultado do processo deve ser reparativo ou restaurativo, e exclui ações que podem conduzir a resultados reparativos sem a participação conjunta das partes, deixando de fora, por exemplo, mediações indiretas ou serviços de apoio às vítimas.

Além do debate em torno ao conceito, ainda deve ser salientado que o termo justiça restaurativa acaba por ser empregado em diversas situações, ainda que em campos não judiciais - como, por exemplo, na resolução de conflitos escolares, hospitais, empresas e, até mesmo, em comunidades online. Tais utilizações propiciam um uso amplo dos procedimentos e das propostas do modelo em questão, mas oportunizam, com isso, um leque de aplicações e possibilidades que escapam a qualquer tentativa de definição ou delimitação do que possa ser e com qual finalidade devem ser utilizados os procedimentos e métodos restaurativos especificamente em relação ao fenômeno criminal (Walgrave, 2008, p. 16-18). No presente trabalho, a justiça restaurativa será trabalhada exclusivamente em relação às instâncias judiciais e, nesse contexto, o enfoque será voltado apenas à justiça criminal.

Importante salientar, portanto, que, antes de ser considerada uma ideia fechada e acabada, trata-se, primordialmente, de uma proposta conceitual que continua aberta. Sica $(2007$, p. 10) refere que "a justiça restaurativa é uma prática ou, mais precisamente, um conjunto de práticas em busca de uma teoria". Pallamolla (2009, p. 54), por sua vez, acentua que "a justiça restaurativa possui um conceito não só aberto como, também, fluido, pois vem sendo modificado, assim como suas práticas, desde os primeiros estudos e experiências restaurativas".

E essa construção ainda em aberto e em constante movimento é, paradoxalmente, um dos pontos mais positivos da justiça restaurativa, pois não há um engessamento de sua forma de aplicação e, portanto, os casos-padrão e as respostas-receituário permanecem indeterminadas, na busca de adaptação a cada caso e aos seus contextos culturais. Como referem Shapland et al. (2006, p. 507), a justiça restaurativa "deve ser, frequentemente de forma bastante dolorosa, produzida a partir de seus ingredientes básicos pelos participantes específicos que vierem a se reunir em razão da ofensa". ${ }^{5}$

\footnotetext{
5 Conferir, igualmente, Walgrave (2008).
} 


\section{A justiça restaurativa na Bélgica: autonomia e conexão com o sistema de justiça criminal}

Realizada a breve exposição conceitual acima, neste momento será exposto o sistema belga de justiça restaurativa. Com a finalidade de averiguar os seus aspectos mais importantes, foi realizada pesquisa bibliográfica sobre a legislação e o histórico da justiça restaurativa naquele país. E para verificar a forma como a previsão legal é aplicada, foram realizadas entrevistas com mediadores atuantes no país, assim como com acadêmicos cujas pesquisas são voltadas para a temática da justiça restaurativa no cenário europeu. ${ }^{6}$

Tais entrevistas tinham como propósito verificar a percepção tanto dos mediadores (práticos) quanto dos acadêmicos (teóricos) sobre a efetividade da justiça restaurativa para administrar conflitos criminais, e desde uma perspectiva crítica sobre o sistema penal, pretendeu-se igualmente questionar o potencial dos mecanismos restaurativos para reduzir a incidência do sistema penal no corpo social.

As entrevistas com acadêmicos foram realizadas sem um roteiro previamente estruturado, de forma a tornar o diálogo o mais livre possível. Tomou-se como eixo central, entretanto, as possibilidades de redução do uso do sistema penal a partir da interferência das práticas restaurativas.

Já as entrevistas realizadas com mediadores seguiram um roteiro préestruturado, elaborado com perguntas gerais, envolvendo a justiça restaurativa e o funcionamento dos serviços oferecidos à população na Comunidade Flamenca (norte do país), e com perguntas específicas, ligadas à questão da possível redução do sistema penal através dos mecanismos restaurativos.

Em relação aos mediadores, foram realizadas entrevistas com membros do Serviço de Mediação da cidade de Leuven. ${ }^{7}$ A título complementar, foram também realizadas entrevistas com mediadores holandeses, atuantes em Amsterdam e arredores; com mediadoras espanholas, atuantes na cidade de Barcelona; e com membros do Serviço Nacional de Mediação da Noruega, com atuação na cidade de Oslo.

Desta forma, seguindo o que Luciano Oliveira chama de "metodologia de baixa complexidade" (2004, p. 164), pretendeu-se agregar ao presente trabalho uma perspectiva mais dinâmica, que abordasse também a percepção

\footnotetext{
6 Ambas as pesquisas (bibliográfica e empírica) foram possíveis em função de estágio de doutoramento realizado junto ao Instituto de Criminologia de Leuven (vinculado à Faculdade de Direito da Universidade de Leuven), no período de dezembro de 2010 a junho de 2011, com bolsa de doutorado "sanduíche" da Capes (processo n. 3770-10-9).

7 Cidade situada a aproximadamente 30 quilômetros a leste da capital Bruxelas, na região Flamenca.
} 
das pessoas que atuam diretamente com a justiça restaurativa e/ou que pesquisam sobre o tema, a fim de melhor compreender a sua potencialidade, as dificuldades enfrentadas com o seu uso, e os seus pontos positivos e negativos. Abandonando a análise meramente legislativa e conceitual, buscou-se verificar se as previsões legais do ordenamento jurídico belga são efetivamente aplicadas, quais são os resultados desta aplicação e qual é a percepção dos atores do sistema restaurativo sobre este quadro.

Como se percebe, não houve a pretensão de conduzir a pesquisa com amparo em uma metodologia rigorosa de pesquisa empírica: procurou-se apenas complementar a análise bibliográfica já existente com a abordagem ilustrativa de um caso concreto - a justiça restaurativa na Bélgica - e com as entrevistas realizadas com os operadores deste sistema, com a finalidade de verificar os caminhos e as opções adotadas, bem como se houve resistência por parte dos atores jurídicos para a sua implementação e quais os resultados obtidos. Entende-se que a ilustração de um caso concreto pode colaborar para uma melhor compreensão sobre o modelo restaurativo como um todo, bem como sobre os problemas enfrentados durante a implementação da justiça restaurativa, ainda que em país(es) com diferenças evidentes em relação ao Brasil.

Cumpre ressaltar, no entanto, que as diferenças no campo jurídico, ao contrário do que se imaginava quando do início das entrevistas, não podem ser consideradas muito salientes. Conforme relatado pela totalidade dos mediadores e acadêmicos belgas, as faculdades de direito do país são conservadoras; os operadores jurídicos (juízes, advogados e promotores), em sua ampla maioria, são formados a partir de um viés técnico-burocrático e não simpatizam com a justiça restaurativa; e a Bélgica, assim como diversos países ocidentais, apresenta a mesma demanda por ampliação do controle penal e um crescente número de apenados.

Pelo menos em relação ao campo jurídico-penal, portanto, foi possível verificar que as diferenças entre Brasil e Bélgica não impedem a realização desta análise, até mesmo porque as diferenças se constituem igualmente como dados relevantes para um trabalho comparativo, que não deve buscar apenas semelhanças, mas justamente contrastes entre os modelos analisados.

\section{A previsão legal da mediação vítima-ofensor na Bélgica e seus efeitos no processo penal}

O largo período de tempo desde que a justiça restaurativa se encontra em operação na Bélgica, a sua abrangência e os diversos estudos e 
pesquisas $^{8}$ sobre esta experiência (em especial na Comunidade Flamenca, localizada na parte norte do país) tornam o exemplo belga propício para amplas e profundas análises práticas e teóricas.

As primeiras iniciativas ocorreram no final da década de 1980, na esfera da justiça juvenil, e possuíam uma finalidade pedagógica. Diversas outras iniciativas foram realizadas desde então, apesar da referida lei não fazer menção à justiça restaurativa ou à mediação. A falta de uma base legal para a promoção da mediação, a ausência de políticas públicas coerentes em nível federal e Comunitário e de orçamento específico para a execução de programas locais, bem como os constantes conflitos de competência entre os diferentes níveis políticos da Federação, são apontadas como as principais causas para o lento desenvolvimento da justiça juvenil restaurativa entre o final dos anos $1980 \mathrm{e}$ meados dos anos 1990 (Aertsen, 2006, p. 68-69).

Ainda em relação à justiça juvenil, em 1999 foram implementados programas de justiça juvenil restaurativa em todos os distritos judiciais da Comunidade Flamenca, com a adoção de três distintos modelos: mediação vítima-ofensor, serviço comunitário e programas de treinamento. Tais modelos são aplicados por ONGs locais, que recebem subsídios para atender a população. A Comunidade Francesa (sul) adotou política semelhante. Além disto, a Universidade de Leuven liderou, a partir do ano 2000, um projeto-piloto de conferências restaurativas, voltado para delitos graves (Aertsen, 2006, p. 70).

Por fim, em 2006, por meio de alterações legislativas em nível federal, a Lei Juvenil de 1965 foi alterada, com a inclusão da mediação e das conferências restaurativas em posição mais clara e central, e instituiu que os juízes devem dar preferência pelas alternativas restaurativas de resolução de conflitos, bem como que os promotores devem necessariamente considerar a possibilidade de uso da mediação antes de encaminhar o caso ao Judiciário (Van Doosselaere; Vanfraechem, 2010, p. 4).

Em relação à justiça criminal para adultos (maiores de 18 anos), a justiça restaurativa apresenta um desenvolvimento mais acelerado do que a justiça juvenil. De 1991 em diante, diversos programas de mediação foram implementados:

a) a mediação penal, ${ }^{9}$ que ocorre no âmbito do Ministério Público (durante ou após a investigação policial, mas antes do oferecimento

8 Para informações completas sobre as pesquisas realizadas pelos integrantes da Linha de Pesquisa em Justiça Restaurativa do Instituto de Criminologia de Leuven, da Universidade de Leuven, conferir: <http://www.law.kuleuven.be/linc/onderzoek/linc-rj-research-brochure-2011.pdf>.

9 Instituída pela Lei de 10 de fevereiro de 1994, que regulamentou o procedimento para a mediação em matéria penal. 
da denúncia), e é realizada por assistentes de mediação em casos cuja pena não supera os dois anos de prisão (Aertsen, 2006, p. 71; Aertsen, 2012, p. 265);

b) a mediação para a reparação (mediation for redress), ${ }^{10}$ que desde junho de 2005 faz parte da legislação federal (Códigos Penal e de Processo Penal belgas) e determina que as partes envolvidas no conflito devem ser informadas sobre o serviço de mediação, que poderá ser realizado em qualquer fase do processo penal ou até mesmo depois da sentença, durante a execução da pena. Neste caso, as mediações são realizadas por duas ONGs: Suggnomè, na Comunidade Flamenca (norte), e Médiante, na Comunidade Valônica (sul) (Aertsen, 2006, p. 71-72; Aertsen, 2012, p. 265);

c) a mediação na fase policial, mais comum na região Flamenca e nos arredores de Bruxelas, apesar de ocorrerem em sede policial, são realizadas por servidores públicos civis, especialmente em casos de pequenas ofensas ao patrimônio (eventualmente praticados com violência), em que há clareza sobre os danos materiais ou financeiros e quando um acordo pode ser alcançado para resolver o conflito (Aertsen, 2006, p. 71-72; Aertsen, 2012, p. 265).

A justiça restaurativa, portanto, é ofertada predominantemente por meio da mediação vítima-ofensor (como de regra nos países europeus), e está disponível em todas as etapas processuais: durante a fase policial (de investigação); como uma alternativa ao processo; em paralelo ao processo; e após a sentença (antes, durante ou depois da execução da pena) (Aertsen, 2012, p. 265).

A lei de 10 de fevereiro de 1994 instituiu a mediação penal no artigo 216 do Código de Processo Penal belga, mas a manteve restrita ao âmbito de atuação do Ministério Público, que pode ofertá-la às partes durante ou após a investigação policial, mas sempre antes do oferecimento da denúncia, em casos cuja pena não supera os dois anos de prisão.

Já a lei de 22 de junho de 2005, que instituiu a mediação para qualquer fase do processo penal (mediação para a reparação), estabelece que o serviço de mediação deve ser organizado e administrado por ONGs privadas, sob a supervisão de uma Comissão Deontológica sobre a Mediação (Van Camp; De Souter, s. d., p. 10).

Pautado pelos princípios da voluntariedade e da confidencialidade, o artigo $3^{\circ}$ da Lei de Introdução ao Código Processual Penal belga dispõe que a

\footnotetext{
${ }^{10}$ Instituída pela Lei de 22 de junho de 2005, que introduziu a possibilidade do uso da mediação no Código de Processo Penal.
} 
mediação é um processo que permite que as partes envolvidas em um conflito possam participar, de forma ativa, voluntária e em total confidencialidade, para resolver as dificuldades oriundas de um delito, com a ajuda de um mediador neutro, que deverá facilitar a comunicação entre as partes e ajudá-las a atingir um acordo por contra própria. O objetivo do acordo deve abarcar a pacificação do conflito e a restauração da relação entre os envolvidos.

Os parâmetros acima foram inspirados pela Recomendação 19, que tratou de mediação em matéria penal, e foi emitida em 15 de setembro de 1999 pelo Comitê de Ministros do Conselho da Europa. A mencionada definição apresenta as palavras-chave sobre o quadro em que o processo de mediação deve ocorrer: voluntariedade, confidencialidade, participação ativa, apoio neutro e comunicação.

Apesar de ser descrita como um processo pela lei belga, não foi estabelecida a forma como o procedimento da mediação deve ocorrer. Ademais, as partes devem determinar o curso da mediação, que deve ser entendido como um processo único ao refletir expressões individuais e as necessidades das partes. A "pacificação" mencionada na lei abarca as relações entre as partes envolvidas no conflito e a relação delas com a sociedade, e "a noção de 'restauração' deve ser considerada em sentido amplo, e pode incluir a reparação das perdas materiais e imateriais" (Van Camp; De Souter, s. d., p. 7).

A lei em questão (de 22 de junho de 2005), além de não definir o formato do processo de mediação, igualmente não estabelece quantos encontros devem ser realizados para que a mediação seja encerrada. Ao mesmo tempo, não excluiu a mediação indireta ${ }^{11}$ e tampouco a participação do advogado no serviço, mas limitou a atuação deste profissional ao apoio e aconselhamento do cliente, em especial quando da formalização do acordo, não podendo, em hipótese alguma, representá-lo nos encontros (Van Camp;De Souter, s. d., p. 11).

As ONGs, por sua vez, para receberem a certificação estatal de reconhecimento pelos serviços de mediação, devem observar os critérios estabelecidos pelo Decreto Real de 26 de janeiro de 2006. Dentre eles, podese destacar: (a) ser uma organização sem fins lucrativos; (b) ter a prática da mediação como propósito principal; (c) oferecer performance regular e efetiva em relação ao serviço de mediação; (d) trabalhar com pessoas que tenham conhecimento suficiente e competência para realizar a mediação; (e) ter um Conselho de Administração cujos membros possuam conhecimento

${ }^{11}$ Dados da ONG Suggnomè revelam que a ampla maioria das mediações é realizada de forma indireta. Em 2009, as mediações indiretas somaram 62\%, enquanto em 2010 esse número aumentou para $68 \%$. 
e experiência em matéria psicossocial, legal, ética e mediação; (f) trabalhar com equipe multidisciplinar; (g) fornecer apoio especializado à equipe; (h) oferecer à equipe a possibilidade de treinamento permanente; (i) observar o código deontológico criado pela Comissão Deontológica sobre Mediação; e (j) possuir infraestrutura adequada para realizar o serviço de mediação (em especial quanto à garantia da confidencialidade), e que seja de fácil acesso por transporte público. Em alguns casos, a certificação das ONGs poderá ser revogada pelo próprio Ministério da Justiça (Van Camp; De Souter, s. d., p. 10-11).

Por fim, cumpre ressaltar que a Lei de 2005 estabelece que o sucesso da mediação não deve ser avaliado pelo resultado do encontro. O memorando explicativo da lei refere que "a mediação, como um processo de comunicação, é de igual importância ao eventual acordo atingido pelas partes. A oportunidade de se comunicar pode em si ser um passo crucial para a pacificação e a restauração" (Van Camp; De Souter, s. d., p. 11-12).

\section{Dificuldades iniciais e consolidação do modelo restaurativo}

Aspecto interessante do caso belga diz respeito às primeiras iniciativas com a justiça restaurativa. Em um primeiro momento, eram voltadas para os adolescentes que se encontravam em conflito com a lei, inseridas no contexto das propostas pedagógicas e protetivas da lei da Justiça Juvenil de 1965. Quatro ONGs realizaram os primeiros experimentos (Oikoten, em Leuven; Arpège, em Liège; G.A.C.E.P., em Charleroi; e Radian, em Bruxelas), inspirados nas suas experiências com serviços comunitários (Van Camp; De Souter, s. d., p. 24).

De acordo com relato de um mediador pioneiro em mediação no país (hoje também um acadêmico, pois realiza estudos de doutorado em reconhecida Universidade belga), os primeiros casos de mediação na cidade de Leuven foram realizados pela ONG Oikoten, onde trabalhava. Esta organização era responsável, à época, por organizar e aplicar medidas educativas aos infratores juvenis. $^{12}$

Incomodados com a forma como os adolescentes encaravam a sua situação, os agentes responsáveis pela aplicação das medidas decidiram

\footnotetext{
12 Não ficou claro durante a entrevista se estas medidas eram impostas pelo Judiciário e apenas aplicadas pela ONG, ou se havia algum tipo de convênio com o sistema de justiça para atender adolescentes que cumpriam medidas em meio aberto. O que restou claro é que a ONG tinha competência para a realização deste trabalho, e dispunha de respaldo para trabalhar com diversas perspectivas de medidas, desde que pedagógicas e em consonância com a lei da Justiça Juvenil de 1965.
} 
pensar em alternativas realistas e viáveis de serem utilizadas, mas que tivessem condições efetivas de permitir aos adolescentes a recuperação da sua autoestima, geralmente afetada em função do sentimento negativo que as medidas determinadas pelo juiz lhes gerava.

Nesse contexto de busca por algo realizável, mas ainda não experimentado, chegou-se à conclusão de que era necessária uma atividade que permitisse aos adolescentes a percepção de que são capazes de cumprir tarefas e objetivos significativos. Segundo o entrevistado (mediador belga), “após a realização destas tarefas ou objetivos, ninguém mais poderia dizer que eles não eram capazes de fazer nada".

Tal atividade, naturalmente, não poderia ser convencional. Para atingir esses objetivos, resolveu-se que deveria possuir um significado simbólico considerável, e então foi proposto que se percorresse, a pé, o trajeto entre Leuven (Bélgica) e Santiago de Compostela (Espanha): a distância de três mil quilômetros que separa as duas cidades e as dificuldades que seriam enfrentadas no caminho poderiam ser os ingredientes que faltavam nas medidas pedagógicas aplicadas pelo Judiciário - em especial os serviços comunitários, pois eram percebidos como verdadeiras punições aos adolescentes infratores e pouca conexão apresentavam com a infração praticada.

Após a realização da caminhada, os membros da ONG continuaram a pensar em medidas realistas e próximas à experiência humana, já que a caminhada dificilmente seria repetida. Em momento não esclarecidamente determinado, os membros concluíram: "se colocarmos os adolescentes em contato com as suas vítimas, talvez alguma coisa interessante possa acontecer" (Entrevistado: mediador belga).

Inicialmente, esperava-se que as vítimas lhes dissessem que tipo de serviço comunitário seria útil para reparar o dano que sofreram. No entanto, em contato com algumas vítimas, perceberam que elas não estavam interessadas com o serviço comunitário, mas em algo mais concreto - em especial, na recuperação do bem que lhes havia sido subtraído ou danificado:

Como os adolescentes não tinham dinheiro ou bens, quem acabava pagando eram os seus pais. Eles estavam preparados para se desculpar, mas como não havia notícias de experiências parecidas anteriores, não se sabia no que isso poderia resultar. As próprias vítimas perceberam que o importante não era o dinheiro, mas que os próprios ofensores deviam fazer alguma coisa, e não os seus pais. Por este motivo, foi organizado um fundo para ressarcimento de vítimas de delitos, e desta forma os ofensores podiam solicitar um apoio para reparar parte do dano da vítima e poderiam também trabalhar para compensar o restante (Entrevistado: mediador belga). 
Por se tratar de uma iniciativa que apresentou bons resultados, a ONG passou a buscar novos casos. Em contato com o Ministério Público, houve a promessa de que caso os encontros resultassem em um acordo, o processo seria arquivado. O promotor responsável se comprometeu a encaminhar casos, mas enviou apenas aqueles cujas infrações eram leves demais, não envolvendo sequer um dano concreto às vítimas. Nas palavras do entrevistado (mediador belga), eram "casos ridículos. As vítimas ficavam espantadas com o nosso contato, pois nem elas percebiam os casos como dignos de intervenção estatal".

Questionando-se onde poderiam estar as resistências para um maior encaminhamento de casos, percebeu-se que o serviço de apoio às vítimas era o principal responsável pelo efeito de revitimização, dada a excessiva proteção das vítimas, caracterizando-se, conforme o relato do entrevistado, em verdadeiras blindagens, por sequer permitir que as vítimas se manifestassem. A Ordem dos Advogados local igualmente resistia à proposta, referindo que não havia previsão e proteção legal para o que era realizado, e que propiciava o retorno do uso da vingança privada - além, é claro, do fato de não ser mais necessário o serviço dos advogados na mediação, caso as partes assim o desejassem.

Ambas as resistências, segundo o entrevistado, não se justificavam, diante da satisfação das vítimas com o serviço oferecido. Ademais, as vítimas estavam mais preocupadas com o papel educacional que a mediação poderia assumir, e não com eventuais punições ou vinganças. De um modo geral, refere o entrevistado, as vítimas possuem boas condições de pensar em uma alternativa interessante para o caso.

Até então, a ONG concluiu que era uma ideia interessante contatar as vítimas, e que isto não representava um perigo para os ofensores. Os problemas verificados, entretanto, foram três: primeiro, concluiu-se que o que estava sendo realizado possibilitava o aumento da rede de controle social, pois pequenos casos, que costumavam ser arquivados pelo Ministério Público em função do excesso de trabalho, poderiam voltar a ser objeto de algum tipo de controle. O segundo problema estava relacionado ao fato de os ofensores passarem a forçar a realização dos acordos, pois ao ouvir do promotor que se o caso fosse mediado e resolvido, o processo seria arquivado, o ofensor passava a tentar o acordo de todas as formas possíveis. Por fim, do segundo problema surgiu o terceiro, pois as vítimas, em alguns casos, passaram a se sentir usadas: com o pedido de desculpas do ofensor, o promotor arquivava os processos e a vítima não obtinha o retorno que desejava, sentindo-se insatisfeita com o resultado final da mediação. 
Os poucos e irrisórios casos enviados pelo Ministério Público e os problemas relatados acima fizeram com que não houvesse mais interesse no acordo com a Promotoria. Para suprir esta lacuna, foram investidos tempo e trabalho na divulgação do serviço de mediação para a sociedade, que seria oferecido de forma autônoma em relação ao sistema de justiça. A divulgação, segundo o entrevistado (mediador belga), envolvia a seguinte mensagem: "se você cometeu uma ofensa, ou se você se sente culpado por algum conflito ou se é uma vítima de algo e quer solucionar o seu caso, então nós estamos preparados para mediar".

De acordo com as palavras do entrevistado, a divulgação

[...] foi um grande sucesso: as pessoas estavam muito interessadas [...]. Nós éramos convidados para encontros de final de tarde e discussões, com todo tipo de pessoas - professores, psicólogos, operadores jurídicos, policiais - todos diziam: "sim, que grande ideia, uma coisa positiva fora do sistema de justiça" (Entrevistado: mediador belga).

E esta era a posição da ONG: manter-se fora do sistema judicial, para atuar de forma autônoma: "nós estamos fazendo mediação, mas sem qualquer relação com o sistema. O nosso serviço está lá para os clientes, para as pessoas" (Entrevistado: mediador belga).

Entretanto, apenas dois ou três casos de mediação foram realizados em um período de dois anos, o que não justificava o investimento de tempo e trabalho realizado. Conforme o relato do entrevistado (mediador belga), concluiu-se que "se tratava de um grande desastre! Nós distribuímos dez mil panfletos e as pessoas não apareceram".

Após algumas discussões, os membros da ONG concordaram que a baixa procura poderia estar relacionada com o fato de o serviço ser oferecido de forma paralela ao sistema judicial, sem a segurança legal sobre o que poderia acontecer após a mediação:

Acredito que estávamos certos à época, pois é um problema de segurança legal. Se nós estivermos brabos um com o outro e você quebrar o meu carro, então você pode, é claro, tentar fazer um acordo comigo, mas você não tem noção se o caso será judicializado, você não tem ideia de onde isto pode parar (Entrevistado: mediador belga).

A ingenuidade, para o entrevistado, estava justamente nisso, pois os crimes e as ofensas não são apenas meros conflitos - são mais do que isto: trata-se de 
[...] uma situação em que há, pelo menos, a possibilidade de intervenção pública, e por haver esta questão de ordem pública envolvida, as partes não poderão estar em pé de igualdade na mediação: o ofensor sempre estará em posição inferior, pois ele é que deverá fazer algo pela vítima (Entrevistado: mediador belga).

Por este motivo, é importante que a mediação tenha um mínimo de segurança jurídica, para que as posições das partes (vítima ou ofensor) sejam claras em termos legais:

Em termos formais, vítima e ofensor são produtos do sistema legal. Você não os encontra na natureza, o que significa que o status da vítima é rodeado de direitos e garantias, e da mesma forma o status do ofensor, e isto já têm uma relação com o sistema. Então, se você gosta disto ou não, e você organizar um serviço de mediação vítimaofensor, você deve fazer isto com o sistema (Entrevistado: mediador belga).

Algumas vezes, refere o entrevistado, as pessoas o consideram "pouco radical", por levar o sistema judicial muito a sério. A sua resposta, todavia, é objetiva:

Eu não concordo com isto. Eu concordo que levo o sistema a sério, mas faço isto em razão dos meus clientes. Penso que, se você não levar o sistema (e o estado de direito) muito a sério, você compromete a posição e a segurança jurídica do seu cliente na mediação vítima-ofensor. [...] Seria um pouco ingênuo e algo negligente fazermos isto por conta própria (Entrevistado: mediador belga).

Com isto, a conclusão a que se chegou foi que era necessário ter contato com o sistema judicial - não apenas em função da segurança jurídica, mas principalmente para que as pessoas tivessem clareza sobre a sua posição no procedimento e sobre os seus direitos.

Além disto, segundo o entrevistado, era importante que os operadores do sistema judicial tivessem conhecimento da mediação nos casos concretos, pois isto lhes permitia referir aos seus clientes que o Ministério Público sabia da oferta de mediação, e que o ofensor não seria considerado culpado por ter aceitado participar. Em alguns casos, as partes compareciam às audiências perante o juiz e apresentavam o resultado do acordo, mas quando o juiz e o promotor não tinham conhecimento de que houvera um acordo por meio da mediação, ambas as partes acabavam, de uma forma ou de outra, prejudicadas 
- em especial a vítima, que passaria por um segundo (ou terceiro) processo de vitimização. Isto devia ser evitado, e este é o motivo pelo qual era necessário esclarecer a situação com o MP e o Judiciário.

Suponha que você é um juiz, e que de tempos em tempos as pessoas aparecem com um acordo. Mas suponha que você não sabe nada e não tem nenhuma garantia sobre a qualidade da mediação - então isto é desafiador, porque você não sabe em que circunstâncias este acordo foi assinado, e talvez o acordo seja fruto de pressão ou de abuso de uma parte sobre a outra, você não sabe. Como você poderia levar este acordo em consideração na sua decisão, se você não sabe se as partes abusaram uma das outras? Por estas razões, é óbvio que o Judiciário deve ao menos ter algumas garantias sobre a natureza e a qualidade, sobre o que é a mediação, e também algum controle, pois eles sabem que há um acordo e um serviço de mediação envolvidos (Entrevistado: mediador belga).

A partir desta conclusão, foi buscado novamente o apoio do Ministério Público, para que tomasse conhecimento oficial sobre o que estava acontecendo e encaminhasse casos. Desta vez, porém, foi solicitado que o promotor demonstrasse às partes o seu interesse no resultado da mediação, mas não oferecesse garantias de que os acordos poderiam influenciar na decisão de denunciar ou não o ofensor. ${ }^{13}$

O grande problema é que muitos promotores disseram que 'sim, é uma boa ideia, [...] mas como promotor, eu devo processar as pessoas. Este é o meu papel. Então, por qual motivo eu devo oportunizar às partes a mediação, qual o meu interesse nisso, como devo justificar isto institucionalmente?' [...] Eu acho que você pode dizer de forma muito firme que [...] sim, você tem um interesse, há um interesse objetivo na mediação para você, por causa do princípio da subsidiariedade, o que significa que se você quer considerar o caso em termos da real necessidade de processar, então você deve checar se há outras soluções [...]. Se você não fizer isto, você não cumpre o seu papel da forma adequada. Nós, o povo, podemos esperar que você tenha curiosidade sobre a nossa capacidade de resolver os nossos próprios casos. Pelo menos isto (Entrevistado: mediador belga).

Para o entrevistado, isto não significa ignorar a independência do Judiciário, mas tal independência não pode autorizar juízes e promotores a

${ }_{13}$ Osistema processual penal belga nãoprevêo princípio da obrigatoriedade, mas o da oportunidade, ficando a critério do promotor de justiça competente a decisão de oferecer a denúncia ou não, ainda que em determinados casos tenha se convencido sobre a ocorrência do delito. 
viver em torres de marfim e desconhecer o que ocorre na sociedade. $\mathrm{O}$ que se buscava era que a mediação fosse reconhecida, ainda que isto pudesse ser considerado insuficiente.

A ONG, à época (aproximadamente 1992), não tinha mais nenhum caso, pois os promotores não deram credibilidade à proposta de considerar oficialmente a mediação, e o Judiciário não tinha garantias de que o procedimento era realizado de forma séria.

O serviço foi colocado, então, sob suspeita, e o projeto estava prestes a desaparecer. No entanto, os membros da ONG tomaram conhecimento, ao mero acaso, de que a Universidade de Leuven havia iniciado, no ano de 1993, um projeto-piloto de mediação vítima-ofensor com adultos. Após contatar os pesquisadores (liderados por Tony Peters, ${ }^{14}$ do Instituto de Criminologia de Leuven), iniciaram então a trabalhar como mediadores no projeto.

Esta colaboração proporcionou que uma lacuna recíproca fosse suprida: enquanto os mediadores não sabiam como transformar a prática em teoria, os acadêmicos não imaginavam como transformar a teoria em prática. Foi somente após o contato com a universidade que eles descobriram que já existia até um nome para o que eles faziam - justiça restaurativa - e isto não apenas lhes devolveu a credibilidade, mas também proporcionou um enorme alívio e estímulo.

\section{O contexto político e a emergência das leis de 1994 e de 2005}

A partir desta junção entre teoria e prática, inspirada em projeto-piloto de mediação realizado no distrito judicial de Gent, ${ }^{15}$ a Lei de 10 de fevereiro de 1994 instituiu a mediação penal no artigo 216 do Código de Processo Penal belga. Em um contexto de superioridade política do partido de extrema direita Vlaams Blok nas eleições parlamentares de 1991,

[...] o governo federal sentiu uma forte necessidade de desenvolver políticas multifacetadas para enfrentar problemas de insegurança e para recuperar a confiança popular. A mediação penal, como uma medida diversionária no âmbito de atuação do Ministério Público, era parte do programa de governo (Aertsen, 2006, p. 70).

Referida lei teve origem na crítica conservadora de que, apesar de os pequenos crimes serem frequentemente ignorados pelo Ministério Público,

${ }_{14}$ A respeito do referido projeto, conferir em Van Camp e de Souter (s. d., p. 24-25).

15 Cidade localizada a aproximadamente 55 quilômetros a noroeste da capital Bruxelas, na região Flamenca. 
eles eram responsáveis por causar perturbação no meio social, em especial quando praticados com frequência. Conforme relato de Van Camp e De Souter (s. d., p. 7) sobre o contexto de emergência da lei, dizia-se que a sociedade precisava responder aos pequenos delitos ao invés de desconsiderá-los para persecução penal, e a principal razão para tanto envolvia, segundo as autoras, a necessidade da população retomar a confiança no sistema de justiça criminal. Para Ivo Aertsen (2006, p. 70-71), a edição da lei de 1994, ao mesmo tempo em que buscou oferecer uma rápida resposta aos delitos leves, pretendeu também aumentar o apoio às vítimas desses delitos.

Aproximadamente dez anos depois, a edição da Lei de 22 de junho de 2005, que instituiu a mediação em todas as fases do processo penal, foi possível em função da conjuntura favorável no continente europeu para a adoção da justiça restaurativa, e especialmente em função dos projetos-piloto belgas, cujos resultados favoreceram a ampliação dos mecanismos restaurativos (Van Camp; De Souter, s. d., p. 16).

De acordo com Aertsen (2006, p. 72), esta lei é fruto direto da filosofia da justiça restaurativa, por definir a mediação como um processo comunicativo, garantir a confidencialidade dos encontros e instituir a voluntariedade da participação das partes. Os atores do sistema de justiça criminal devem informar as partes sobre a possibilidade de mediarem o conflito em todas as fases do processo penal, até mesmo após a sentença.

O procedimento da mediação, por sua vez, é realizado sempre fora do sistema judicial, na sede das ONGs, por mediadores treinados especialmente para isto, e o seu resultado poderá ser comunicado ao processo, caso essa seja a vontade das partes. O juiz competente, por sua vez, poderá levar o resultado em consideração no momento de prolatar a sentença (Aertsen, 2006, p. 72).

\section{Impressões sobre a importância e o impacto da justiça restaurativa na Bélgica}

Apesar de não servir como modelo direto para adoção no Brasil, dadas as consideráveis diferenças (sociais, culturais etc.) entre os dois países, o caso belga apresenta diversos aspectos que merecem uma maior atenção. De um modo geral, é possível referir que os pontos em destaque tratam, resumidamente, sobre: (a) a forma como a justiça restaurativa foi instituída; (b) o local onde é realizada; e (c) a maneira como se relaciona com o sistema penal tradicional e os efeitos que gera no processo penal.

Em relação ao primeiro aspecto, chama a atenção o fato de que, no ano de 2001, o então Ministro da Justiça instituiu "um grupo de trabalho interdisciplinar para examinar as possibilidades de introduzir a base legal 
para a mediação no Código de Processo Penal" (Van Camp; De Souter, s. d., p. 17). Trata-se de ponto positivo do sistema de mediação belga (em especial, a mediação para todas as fases do processo): ao incorporar o conhecimento de mediadores atuantes, a técnica legislativa se limitou a inserir o estritamente necessário para o funcionamento do serviço de mediação e, a partir das experiências com projetos anteriores, reduziu as margens de colonização do sistema restaurativo pela justiça criminal tradicional.

Acerca do segundo aspecto, destaca-se o fato de que os encontros são conduzidos em ambiente diverso ao do sistema de justiça criminal, em geral nas ONGs Suggnomè e Médiante. Até mesmo quando realizada durante a execução da pena, após o trânsito em julgado da sentença condenatória, os encontros são realizados fora do ambiente prisional, com a finalidade de não afrontar os princípios restaurativos (Van Droogenbroeck, 2010, p. 231).

Por fim, o fato de a mediação penal gerar diversos efeitos no sistema penal tradicional igualmente merece destaque: se realizada em sede policial e envolver delitos leves, a investigação poderá ser arquivada; se realizada pelo promotor de justiça e o crime em questão não prever uma pena superior a dois anos, o promotor poderá optar entre denunciar ou não o acusado; e, ainda, se realizada antes ou durante o processo penal e for levada a conhecimento do juiz competente, este necessariamente deverá mencionar que está ciente do resultado da mediação e poderá levá-lo em consideração no momento de proferir a sentença, reduzindo a pena ou absolvendo o acusado, se considerar adequado.

A ênfase na faculdade do juiz levar em conta ou não o resultado da mediação quando do momento de sentenciar está diretamente relacionada com a posição da vítima, que poderá não se sentir à vontade para participar de uma mediação caso saiba, antecipadamente, que o ofensor será necessariamente beneficiado em função de um encontro bem sucedido. A questão não envolve eventual temor da vítima com a possível redução da pena do condenado, mas diz respeito, antes disso, à possibilidade do encontro restaurativo não ser realizado com a máxima liberdade possível pelas partes.

Contudo, apesar da ampla regulamentação da justiça restaurativa no estado belga, ainda não é possível constatar um impacto significativo na redução da incidência do sistema de justiça criminal tradicional. Inobstante esta constatação, todos os mediadores e acadêmicos entrevistados foram enfáticos ao mencionar que, com o passar do tempo, este impacto poderá vir a ser verificado.

O desconhecimento sobre a forma de funcionamento e os efeitos que um mecanismo restaurativo pode causar no processo penal tradicional são fatores 
determinantes, segundo os entrevistados, para a baixa quantidade de casos em comparação com a justiça criminal tradicional. Esta desproporcionalidade, no entanto, é percebida com naturalidade, diante dos mais de duzentos anos de funcionamento do sistema tradicional e dos curtos sete anos desde a instituição do sistema restaurativo na legislação da Bélgica.

Outro fator de destaque é o reconhecimento internacional do sistema restaurativo belga, justamente em função da autonomia e da forma como oferece a mediação e da sua relação com o processo penal. Tanto os mediadores quanto os acadêmicos entrevistados ressaltaram que a autonomia da justiça restaurativa no modelo belga é um aspecto consideravelmente positivo. Ao atribuir a operadores não necessariamente jurídicos a condução dos casos, as chances de colonização do sistema pelos vícios e formalismos do modelo tradicional de justiça criminal são significativamente reduzidas.

Aertsen (2006, p. 73-75), por sua vez, destaca quatro fatores para a consolidação da justiça restaurativa na Bélgica: (a) a previsão da mediação na legislação federal, que desde 2005 possibilitou o seu uso em todas as fases do processo penal e, ainda, estabeleceu a forma de contato com a justiça criminal; (b) o papel desempenhado pelas ONGs, pioneiras no oferecimento do serviço de mediação, por oferecerem este serviço em total sintonia com os princípios restaurativos; (c) os projetos de pesquisa realizados pela Universidade de Leuven, que desde os anos 1990 os realiza em colaboração direta com os mediadores e, no ano 2000, fundou também o Fórum Europeu de Justiça Restaurativa, com sede no Instituto de Criminologia de Leuven, e reúne informações importantes sobre experiências com justiça restaurativa em diversos países europeus e de outros continentes; e (d) as ações em colaboração entre voluntários (membros de ONGs) e acadêmicos, que têm obtido sucesso no convencimento ou no apoio aos órgãos governamentais para a inserção definitiva da justiça restaurativa na agenda política do país.

Os mediadores atuantes em Leuven, de um modo geral, referendaram a constatação de Aertsen sobre a importância das pesquisas realizadas pela Universidade, e mencionaram que, além de contribuir com a análise crítica sobre a forma como os serviços de mediação são oferecidos e realizados, os pesquisadores acabaram por se tornar seus aliados na busca pelo aprimoramento constante do serviço. A ONG Suggnomè e o Serviço de Mediação de Leuven (que, à exceção das suas sedes administrativas, funcionam no mesmo espaço físico), em especial, estão em contato permanente com a Universidade e com as discussões acadêmicas sobre a justiça restaurativa na Comunidade Flamenca. ${ }^{16}$

\footnotetext{
${ }^{16}$ Sobre a colaboração da academia, conferir também: Aertsen (2006, p. 74-75).
} 
Um dos mediadores chegou a mencionar que o Serviço de Mediação de Leuven e a ONG Suggnomè são favorecidos pelo fato de contar com o apoio constante da Universidade: "isto facilita inclusive a divulgação da mediação entre os operadores jurídicos" (Entrevistado: mediador 1 SML). ${ }^{17}$

A percepção do impacto das duas leis que inseriram a mediação no ordenamento jurídico da Bélgica (as referidas leis de 1994 e de 2005), contudo, são diversas. Nota-se uma relativa insatisfação com a primeira e um contentamento mais visível com a segunda.

Os mediadores entrevistados são céticos ao mencionar que a mediação no âmbito do Ministério Público é "menos voluntária, porque se o ofensor paga a multa, estará livre do processo" (Entrevistado: mediador $2-\mathrm{SML}$ ), enquanto a proposta central da justiça restaurativa - promover a comunicação e a participação ativa das partes na resolução do caso - acaba em segundo plano, ou até mesmo esquecida. Segundo Van Camp e De Souter (s. d., p. 31), a mediação no âmbito da promotoria de justiça não surgiu em função da necessidade de aprimorar os princípios da justiça restaurativa, mas, antes disso, tinha como propósito

[...] introduzir outra medida diversionária e [...] assegurar uma resposta imediata e efetiva aos pequenos delitos. Independente do quão legítimo este objetivo possa ser, o procedimento parece instrumentalizar a mediação para uma resposta mais efetiva aos delitos leves, ao invés de promover a comunicação e a participação da vítima e do ofensor.

Conforme Tinneke Van Camp e Anne Lemmone (2005, p. 10-11), os problemas verificados em relação à mediação penal instituída pela Lei de 1994 se resumem ao fato de estar prevista, ao lado de outras medidas diversionárias, apenas como mais uma possibilidade de encerrar o caso, e não como uma possibilidade de mediar efetivamente o conflito.

Esta constatação ratifica as impressões dos entrevistados, e permite concluir que os resultados insatisfatórios alcançados com esta modalidade de mediação são muito próximos do procedimento dos juizados especiais criminais no Brasil, especialmente em relação à frustração gerada nas vítimas pelo amplo uso da transação penal como forma principal de arquivar processos, e não de debater o conflito. ${ }^{18}$

17 SML: Serviço de Mediação de Leuven.

18 A respeito dos problemas enfrentados pelos juizados especiais criminais no Brasil, conferir em Wunderlich e Carvalho (2002; 2004). 
Já em relação à mediação para a reparação, Van Camp e Lemmone (2005, p. 10-11) verificaram resultados positivos a partir de avaliações dos experimentos com esta modalidade no final dos anos 1990 e início dos anos 2000: o nível de satisfação das vítimas era elevado, pois eram envolvidas de forma efetiva na condução do processo, e mesmo que o acordo não fosse possível ao final dos encontros restaurativos, ainda assim se constatou um alto índice de satisfação por parte das vítimas, justamente por terem sido escutadas e levadas em consideração durante o procedimento. Os direitos do ofensor, por sua vez, não eram afetados, e a forma de condução dos encontros igualmente permitiu que tivessem participação ativa na resolução do conflito, ainda que ao final não tenha sido verificada a formalização de um acordo.

Instituída legalmente pela Lei de 2005, este tipo de mediação (aplicável em qualquer fase do processo penal) é vista de forma positiva pelos entrevistados, corroborando os resultados verificados por Van Camp e Lemmone (2005). Ao atender às características centrais da justiça restaurativa e estabelecer um importante canal de comunicação com a justiça criminal tradicional, foi possível implementar um sistema que efetivamente alterasse o panorama tradicional do funcionamento do sistema penal e colocasse tanto a vítima quanto o ofensor em posição ativa, com ampla possibilidade de participação na condução e na resolução dos casos.

O cenário belga aponta, portanto, para uma fusão entre o conhecimento prático e teórico, beneficiado pelo contexto favorável à adoção da justiça restaurativa em todo o continente europeu e por incentivos diretos do parlamento federal ao longo das últimas duas décadas. Com os resultados positivos verificados pelas pesquisas desde os anos 1990, o uso da mediação vítima-ofensor se encontra devidamente institucionalizado, e é utilizado em toda a escala de delitos.

Oferecida e realizada por ONGs acreditadas pelo governo federal, conclui-se, com Aertsen (2006, p. 89), que a justiça restaurativa belga está situada em posição semiautônoma, em um espaço entre o sistema de justiça criminal formal e os meios informais de resolução de conflitos. Apesar da independência organizacional do modelo restaurativo, a sua relação com a justiça criminal é direta, o que faz com que seja, de uma certa forma, dependente do sistema tradicional.

Interessante notar, por fim, o hibridismo político em torno da mediação penal: enquanto os entrevistados (mediadores e acadêmicos) referem a importância do abolicionismo penal para o surgimento da justiça restaurativa no meio acadêmico europeu dos anos 1970-1980, a mediação penal foi introduzida na legislação belga a partir de um programa de governo de extrema 
direita, que viu neste modo de resolução de conflitos uma possibilidade de ampliar o sistema de controle social e repreender prontamente as pequenas ofensas. Os governos seguintes, de orientações políticas diversas, continuaram a dar apoio à justiça restaurativa, ainda que por motivos diferentes.

O motivo principal para que a mediação penal instituída no âmbito das promotorias de justiça (Lei de 1994) não tenha apresentado resultados satisfatórios talvez tenha sua razão exatamente em função da sua proposta original: ao ser instituída como uma forma de melhorar a administração interna do Judiciário, passou a ser utilizada como uma mera ferramenta para o arquivamento maciço dos casos, e não para aumentar a qualidade do sistema judicial.

Não se desconhece, contudo, as críticas ao funcionamento do sistema. Van Camp e Lemmone (2005, p. 7-8) chamam a atenção para o fato de que poucos são os casos conduzidos por meio de mediação direta entre vítima e ofensor, e que não há avaliação em andamento no país sobre a influência do sistema restaurativo quanto à reincidência ou a uma eventual redução de custos. ${ }^{19}$

Os operadores do sistema penal (polícia, promotores de justiça e magistrados), por sua vez, costumam não assumir qualquer tipo de responsabilidade em relação às vítimas dos delitos, por considerarem que esta é uma tarefa dos serviços de apoio às vítimas (Van Camp; Lemmone, 2005, p. 9).

Para os mediadores e acadêmicos belgas entrevistados, entretanto, o sistema está no caminho certo, apesar dos problemas mencionados: a quantidade relativamente baixa de casos (quando comparado com a justiça criminal tradicional) é benéfica, por permitir um acompanhamento mais próximo dos casos e dos resultados alcançados; e, do mesmo modo, não se esperava que apenas em função da inserção da justiça restaurativa na legislação penal houvesse, instantaneamente, um apoio maciço ao novo sistema - pelo contrário: sabe-se que a verificação e posterior divulgação da potencialidade da justiça restaurativa é lenta, e pode levar muitos anos (décadas) para ocorrer. Por fim, as diversas resistências encontradas, provenientes especialmente dos atores jurídicos, são conhecidas desde os primeiros dias da justiça restaurativa no país, e só poderão ser afastadas - se é que um dia serão - com o passar dos anos.

${ }_{19}$ Pesquisa conduzida pelo Smith Institute (Londres, Inglaterra) sobre a justiça restaurativa em países como Reino Unido, Estados Unidos e Austrália, apontou para uma possível redução de gastos públicos com os sistemas de justiça e saúde através do uso mais amplo do modelo restaurativo. Além disso, constatou-se também que a justiça restaurativa, em comparação com a justiça criminal tradicional, apresenta um índice menor de reincidência em relação a crimes violentos (Sherman; Strang, 2007, p. 68-71, 86 e 88). 


\section{Considerações finais}

O que está em jogo quando o assunto é justiça restaurativa não é apenas uma mudança de procedimento, mas, fundamentalmente, uma mudança cultural: o rompimento com o paradigma do crime-castigo é um dos principais aspectos da justiça restaurativa, com a alteração da distribuição de poder entre os envolvidos (partes e operadores jurídicos) e a redefinição da forma como os fatos legalmente classificados como delituosos são interpretados.

A mofada pré-determinação, via códigos ou leis, do que é e do que não é crime, pode vir a se diluir aos poucos, abrindo espaço, tempo e lugar para que as partes decidam o que fazer com os seus casos. $\mathrm{O}$ abandono do modelo em que "terceiros" tomam os seus lugares e as suas dores e dizem, a partir de seus locais de vida - evidentemente outros - o quê e como deve ser feito com os seus conflitos, é inevitável.

Esta devolução do protagonismo às partes tem potencial, portanto, para romper com o sistema de condutas proibidas a priori, para que sejam pensadas a partir do ponto de vista dos próprios envolvidos no episódio. Tem-se, com isto, uma importante abertura para que as partes tragam à discussão as suas variáveis subjetivas, que, na justiça criminal tradicional, não encontram espaço de valorização e são, como regra, tidas como exteriorização de sentimentos irracionais (Achutti, 2011).

A experiência belga mostra, assim, que os temores em relação à participação da vítima na resolução do caso, à consideração dos aspectos subjetivos das partes na condução do procedimento e à perda de poder dos operadores jurídicos não se confirmam na prática. Os efeitos são verificados, ao contrário do que se imagina, em sentido oposto: conforme relato dos mediadores, constatou-se que as partes que optam pelo sistema restaurativo passaram a dar maior credibilidade ao sistema de justiça, especialmente pelo fato da decisão sobre o caso ter sido discutida coletivamente e a versão delas ter sido efetivamente considerada. ${ }^{20}$

Além disso, o resultado obtido no procedimento restaurativo, ao ser encaminhado ao sistema de justiça criminal, pode ou não ser levado em consideração pelo juiz (ao prolatar a sentença) e pelo promotor de justiça (ao oferecer a denúncia), de forma que não se pode afirmar que ocasiona perda de poder aos atores jurídicos no processo penal tradicional. O que há

\footnotetext{
${ }^{20}$ A mesma pesquisa, referida na nota anterior (conduzida pelo Smith Institute), chegou a conclusões semelhantes: verificou-se que este modelo de justiça, ao ampliar o acesso à justiça e permitir que o conflito seja administrado por maneira diversa à da justiça criminal tradicional, tem potencial para aumentar a confiança no sistema de justiça como um todo (Sherman e Strang, 2007, p. 78).
} 
é apenas a inserção de um novo elemento no sistema processual penal, que se não for considerado forte o suficiente para o arquivamento do inquérito ou do processo (antes ou após o oferecimento da denúncia), obriga que juiz e promotor fundamentem a sua decisão de condenar e de oferecer a denúncia, respectivamente.

Esta estrutura não retira poder do estado, mas determina que a percepção das pessoas sobre os seus casos deve ser levada em consideração, ainda que a opção seja pela manutenção da acusação e a condenação do acusado. Tem-se, na verdade, a criação de um novo limite ao poder de punir, que deverá levar em consideração os resultados obtidos por meio da justiça restaurativa antes de ser efetivado.

Ainda foi possível verificar que, apesar de ter pouca incidência no número total de casos criminais, a justiça restaurativa pode ter consequências práticas importantes no sistema de justiça criminal tradicional. Ao permitir a redução da pena ou a absolvição do condenado, e até mesmo o arquivamento do inquérito policial ou do processo penal, tem-se que, a longo prazo, a ampliação do uso das práticas restaurativas no sistema penal poderá ter a sua amplitude reduzida. Apesar de todas as dificuldades, as experiências apresentam resultados positivos, e uma maior divulgação sobre o funcionamento do sistema e sobre as suas consequências poderá colaborar para que os mitos que envolvem o tema sejam derrubados.

Apesar da análise positiva sobre o caso belga, é importante salientar, por fim, que não é possível considerá-lo como um modelo perfeito e acabado e, menos ainda, que pode ser plena e acriticamente adotado no Brasil. As significativas diferenças entre os dois países impedem tal proposição.

Contudo, nada impede que alguns aspectos possam ser levados em consideração deste lado do Atlântico, a começar pela possibilidade de, no processo penal brasileiro, ser inserida a faculdade de o juiz deixar de aplicar determinada sanção ou reduzi-la, conforme o caso, de acordo com a vontade expressa pelas partes durante o encontro restaurativo. Além disso, em determinados casos, quando já houver acordo entre as partes e se tratar de lesão a bem jurídico disponível, não existem razões suficientes para negar valor à vontade das partes sobre a forma como deve ser resolvido o conflito.

Outras particularidades, desde que com a devida cautela, poderiam ser igualmente adotadas no Brasil, inclusive em relação a delitos graves ou que tutelam bens jurídicos indisponíveis. Todavia, o maior empecilho à adoção deste sistema talvez não esteja na forma como deve ser estruturada a justiça restaurativa ou mesmo nas suas consequências para a justiça criminal tradicional, mas nas dimensões continentais do país e na escassa produção 
científica sobre o tema, assim como na quase inexistente análise regular das experiências até aqui conduzidas. $\mathrm{O}$ aumento das pesquisas e de seminários, bem como de debates e avaliações sobre os programas e projetos de justiça restaurativa atualmente em execução (cf. Achutti e Pallamolla, 2012), somados ao respeito às diversidades regionais (e até mesmo locais) existentes no Brasil, poderiam, sem dúvida, colaborar para o avanço da temática em nosso país.

\section{Referências}

ACHUTTI, Daniel. The strangers in criminal procedure: restorative justice as a possibility to overcome the simplicity of the modern paradigm of criminal justice. Oñati Socio-Legal Series, v. 1, n. 2, p. 1-17, 2011.

ACHUTTI, Daniel; PALLAMOLLA, Raffaella. Restorative justice in juvenile courts in Brazil: a brief review of Porto Alegre and São Caetano pilot projects. Universitas Psychologica, Bogotá, v. 11, n. 4, p. 1.093-1.104, 2012.

AERTSEN, Ivo. The intermediate position of restorative justice: the case of Belgium. In: AERTSEN, Ivo; DAEMS, Tom; ROBERT, Luc. Institutionalizing Restorative Justice. Cullompton e Portland: Willan Publishing, 2006.

. Restorative prisons: where are we heading? In: BARABÁS. Tünde; FELLEGI, Borbála; WINDT, Szandra. Responsibility-taking, relationship-building and restoration in prisons. Mediation and restorative justice in prison settings. Budapeste: Instituto Nacional de Criminologia, 2012.

BRAITHWAITE, John. Restorative justice and responsive regulation. Oxford: Oxford Press, 2002.

Van CAMP, Tinneke; LEMMONE, Anne. Critical reflection on the development of

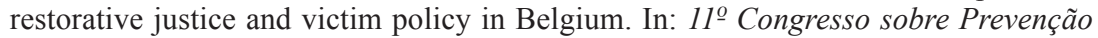
ao Crime e Justiça Criminal da ONU. Tailândia, 2005. Disponível em: <http://www. icclr.law.ubc.ca/Site\%20Map/Events/11UN_papers.htm>. Acesso em: 10 fev. 2011.

Van CAMP, Tinneke; DE SOUTER, Vicky. Restorative justice in Belgium. In: MIERS, David; AERTSEN, Ivo (Eds.). Regulating restorative justice: a comparative study of legislative provision in European Countries. Frankfurt: Verlag für Polizeiwissenschaft, 2012.

Van DOOSSELAERE, Denis; VANFRAECHEM, Inge. Research, practice and policy partnerships. Empirical research on restorative justice in Belgium. In: VANFRAECHEM, Inge; AERTSEN, Ivo; WILLEMSENS, Jolien (Eds.). Restorative justice realities: research in a European context. Haya: Eleven Publishing, 2010.

Van DROOGENBROECK, Bram. Victim offender mediation in severe crimes in Belgium: "what victims need and offenders can offer". In: European best practices of restorative justice in the criminal procedure. Conference Publication. Budapeste: Ministério da Justiça, 2010.

HOYLE, Carolyn. The case for restorative justice. In: HOYLE, Carolyn; CUNNEEN, Chris. Debating restorative justice. Oxford e Portland: Hart Publishing, 2010.

JOHNSTONE, Gerry; VAN NESS, Daniel W. The meaning of restorative justice. In: JOHNSTONE, Gerry; VAN NESS, Daniel W. (Orgs.). Handbook of restorative justice. Cullompton e Portland: Willan Publishing, 2007. 
MARSHALL, Tony. Grassroots initiatives towards restorative justice. In: DUFF, Anthony; MARSHALL, Sandra; DOBASH, Rebecca E.; DOBASH, Russell P. (Eds.). Penal theory and practice. Tradition and innovation in criminal justice. Manchester: Manchester University Press, 1994.

. The evolution of restorative justice in Britain. European Journal on Criminal Policy Research, Heidelberg: Springer, v. 4, n. 4, p. 21-46, 1996.

MORRIS, Alisson. Critiquing the critics: a brief response to critics of restorative justice. The British Journal of Criminology, v. 42, n. 3, p. 596-615, 2002.

Van NESS, Daniel W.; STRONG, Karen Heetderks. Restoring justice: an introduction to restorative justice. 4. ed. New Providence: Anderson Publishing, 2010.

OLIVEIRA, Luciano. Não fale do Código de Hamurábi! A pesquisa sócio-jurídica na pós-graduação em Direito. In: OLIVEIRA, Luciano. Sua Excelência o Comissário e outros ensaios de sociologia jurídica. Rio de Janeiro: Letra Legal, 2004.

PALLAMOLLA, Raffaella da Porciuncula. Justiça restaurativa: da teoria à prática. São Paulo: IBCcrim, 2009.

RUGGIERO, Vincenzo. An abolitionist view of restorative justice. International Journal of Law, Crime and Justice, v. 39, n. 2, p. 100-110, 2011.

SHAPLAND, Joanna et al. Situating restorative justice within criminal justice. Theoretical Criminology, Londres, v. 10, n. 4, p. 505-532, 2006.

SHERMAN, Lawrence; STRANG, Heather. Restorative justice: the evidence. Londres: Smith Institute, 2007. Disponível (versão integral) em: <http://www.sas. upenn.edu/jerrylee/RJ_full_report.pdf>. Acesso em: 9 maio 2012.

SICA, Leonardo. Justiça restaurativa e mediação penal: o novo modelo de justiça criminal e de gestão do crime. Rio de Janeiro: Lumen Juris, 2007.

STRANG, Heather. Repair or revenge: victims and restorative justice. Oxford: Oxford University Press, 2002.

WALGRAVE, Lode. Restorative justice, self-interest and responsible citizenship. Cullompton e Portland: Willan Publishing, 2008.

WUNDERLICH, Alexandre; CARVALHO, Salo de (Orgs.). Diálogos sobre a justiça dialogal: teses e antíteses sobre os processos de informalização e privatização da justiça penal. Rio de Janeiro: Lumen Juris, 2002.

Juris, 2004.

. Novos diálogos sobre os juizados especiais criminais. Rio de Janeiro: Lumen

ZEHR, Howard. Trocando as lentes: um novo foco sobre o crime e a justiça. São Paulo: Palas Athena, 2008.

Data de recebimento: 10/02/2013.

Data de aprovação: 30/03/2013.

Autor correspondente:

Daniel Achutti

Av. Getúlio Vargas, 901, ap. 1702 - Menino Deus

90150-003 Porto Alegre, RS 